\section{Commentary: Time to convert? Minimally invasive surgery following induction immunotherapy}

\author{
Katherine D. Gray, MD, and Matthew J. Bott, MD
}

In the last 5 years, immunotherapeutic agents such as pembrolizumab have become an important treatment option for advanced non-small cell lung cancer (NSCLC). ${ }^{1}$ Results from this patient population, together with the biological rationale of initiating immunotherapy while the tumor and associated antigens are in place, has generated considerable interest for incorporating immunotherapy into multimodality therapy regimens for resectable patients. This small but wellconstructed phase II trial from Tong and colleagues ${ }^{2}$ joins a growing body of literature showing that surgery for resectable NSCLC after immunotherapy can be performed with similar morbidity as resection after traditional induction regimens. ${ }^{3-5}$

This current study is notable compared with previous reports because of the dominant use of minimally invasive techniques $(72 \%)$, despite the previously described complexity of these cases. This is likely a testament to the collective skill of surgeons in this trial but also underscores the importance of building institutional familiarity with new induction protocols so that surgical team members can anticipate intraoperative findings when planning a surgical approach. Although the authors report 3 patients with microscopic residual disease (R1), these cases appear to be unrelated to the thoracoscopic approach and perhaps instead speak to the extent of locoregional disease in these trial patients. However, the use of a minimally invasive technique likely is responsible for the longer operative times in this

From the Department of Thoracic Surgery, Memorial Sloan Kettering Cancer Center, New York, NY

Disclosures: Dr Bott reported receipt of consulting fees from AstraZeneca. Dr Gray reported no conflicts of interest.

The Journal policy requires editors and reviewers to disclose conflicts of interest and to decline handling or reviewing manuscripts for which they may have a conflict of interest. The editors and reviewers of this article have no conflicts of interest.

Received for publication March 23, 2021; revisions received March 23, 2021; accepted for publication March 24, 2021; available ahead of print March 30, 2021. Address for reprints: Matthew J. Bott, MD, Department of Thoracic Surgery, Memorial Sloan Kettering Cancer Center, 1275 York Ave, New York, NY 10065 (E-mail: bottm@mskcc.org).

J Thorac Cardiovasc Surg 2022;163:437-8 $0022-5223 / \$ 36.00$

Copyright $(2021$ Published by Elsevier Inc. on behalf of The American Association for Thoracic Surgery

http://dx.doi.org/10.1016/j.jtcvs.2021.03.086

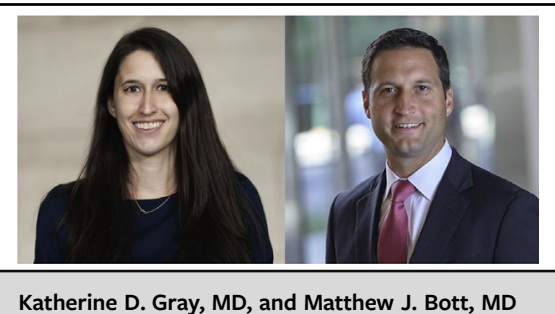

Katherine D. Gray, MD, and Matthew J. Bott, MD

CENTRAL MESSAGE

Minimally invasive resection can

be safely performed after neo-

adjuvant immunotherapy with

pembrolizumab.

study, and morbidity and length of stay were not reduced compared with similar series with a higher proportion of open procedures. Although increased operative times may be a surrogate for difficult dissections, details regarding operative findings (eg, fibrosis) are not elucidated here.

In this series, $80 \%$ of the patients had at least a $50 \%$ pathologic response, $28 \%$ of patients had a major pathologic response, and $12 \%$ had a complete pathologic response after just 2 doses of pembrolizumab, lending credibility to the idea that neoadjuvant immunotherapy may be useful for local disease control before resection. Interestingly, more than onethird of resected patients were upstaged after surgery, and in the overall enrolled cohort of 30 patients, 5 patients had disease progression that precluded resection. This percentage is high compared with that in other studies of preoperative checkpoint inhibition or even neoadjuvant chemotherapy; however, it is possible that these patients had occult metastatic disease before initiation of treatment that was subsequently discovered at the time of surgery. If these data represent true disease progression on single-agent immunotherapy, then perhaps additional biomarkers, such as PD-L1 status or tumor mutation burden, would be helpful to better select patients for this approach. Furthermore, preliminary data suggest encouraging efficacy with combined chemoimmunotherapy, ${ }^{6}$ so this ultimately may be the preferred strategy in some patients.

The authors should be congratulated for this study, which helps lay important groundwork for ongoing phase III trials that will elucidate the optimal multimodal strategies for resectable NSCLC. These findings will be of particular interest to the surgical community, in which the operative implications of these drugs will become increasingly important as they become more widely incorporated into pre-operative regimens. 


\section{References}

1. Mok TSK, Wu YL, Kudaba I, Kowalski DM, Cho BC, Turna HZ, et al. Pembrolizumab versus chemotherapy for previously untreated, PD-L1-expressing, locally advanced or metastatic non-small-cell lung cancer (KEYNOTE-042): a randomised, open-label, controlled, phase 3 trial. Lancet. 2019;393:1819-30.

2. Tong BC, Gu L, Wang X, Wigle DA, Phillips JD, Harpole DH Jr, et al. Perioperative outcomes of pulmonary resection after neoadjuvant pembrolizumab in patients with non-small cell lung cancer. J Thorac Cardiovasc Surg. 2022;163:427-36.

3. Eichhorn F, Klotz LV, Bischoff H, Thomas M, Lasitschka F, Winter H, et al. Neoadjuvant anti-programmed Death-1 immunotherapy by Pembrolizumab in resectable nodal positive stage II/IIIa non-small-cell lung cancer (NSCLC): the NEOMUN trial. BMC Cancer. 2019;19:413.
4. Bott MJ, Yang SC, Park BJ, Adusumilli PS, Rusch VW, Isbell JM, et al. Initial results of pulmonary resection after neoadjuvant nivolumab in patients with resectable non-small cell lung cancer. J Thorac Cardiovasc Surg. 2019;158: 269-76.

5. Cascone T, William WN Jr, Weissferdt A, Leung CH, Lin HY, Pataer A, et al. Neoadjuvant nivolumab or nivolumab plus ipilimumab in operable non-small cell lung cancer: the phase 2 randomized NEOSTAR trial. Nat Med. 2021;27: 504-14.

6. Provencio M, Nadal E, Insa A, García-Campelo MR, Casal-Rubio J, Dómine M, et al. Neoadjuvant chemotherapy and nivolumab in resectable non-small-cell lung cancer (NADIM): an open-label, multicentre, single-arm, phase 2 trial. Lancet Oncol. 2020;21:1413-22.

\section{See Article page 427.}

\section{Commentary: I-O, I-O, there's still some work to go...}

\section{Stephen C. Yang, MD}

In the classic scene of Snow White and the Seven Dwarfs, these fictional characters are singing and whistling the iconic song "Heigh-Ho" as they head off to work. Much like these famed heroes, physicians and patients continue to work on advancing the knowledge of immuno-oncology (I-O) and its role in resectable non-small cell lung cancer (NSCLC).

In this issue of the Journal, Tong and colleagues ${ }^{1}$ present their perioperative outcomes from a multi-institutional prospective phase 2 trial using induction pembrolizumab for resectable stage IB-IIIA NSCLC. They conclude it is a safe regimen, with comparable morbidity compared with noninduction patients, no morbidity, and a respectable conversion rate of $21 \%$, similar to other published induction strategies. Although programmed death-1/programmed cell death ligand 1 status was not available preoperatively for all patients and thus not reported, a major pathologic response rate of $28 \%$ was observed. However, some issues to note are as follows: a 57\% squamous histology; disease progression in 4 patients (perhaps not appreciate at initial

From the Division of Thoracic Surgery, Department of Surgery, Johns Hopkins Medical Institutions, Baltimore, Md.

Disclosures: The author reported no conflicts of interest.

The Journal policy requires editors and reviewers to disclose conflicts of interest and to decline handling or reviewing manuscripts for which they may have a conflict of interest. The editors and reviewers of this article have no conflicts of interest.

Received for publication April 11, 2021; revisions received April 11, 2021; accepted for publication April 12, 2021; available ahead of print April 18, 2021.

Address for reprints: Stephen C. Yang, MD, Division of Thoracic Surgery, The Johns Hopkins Hospital, 600 N. Wolfe St, Blalock 240, Baltimore, MD 21287 (E-mail: syang@jhmi.edu).

J Thorac Cardiovasc Surg 2022;163:438-9

$0022-5223 / \$ 36.00$

Copyright (c) 2021 by The American Association for Thoracic Surgery

http://dx.doi.org/10.1016/j.jtcvs.2021.04.027

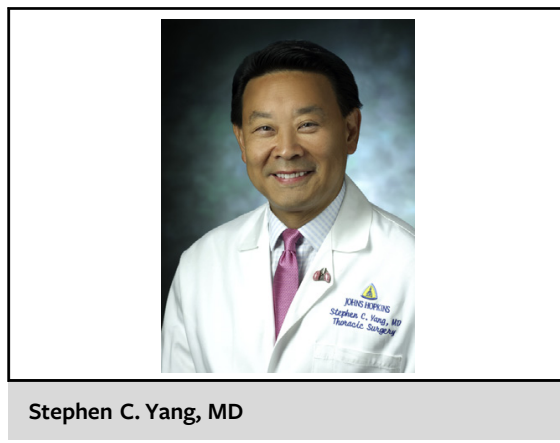

CENTRAL MESSAGE

Single-agent pembrolizumab ap-

pears safe, but much work remains

in clarifying induction $1-O$ strate-

gies, effects on surgical tissue, and

histopathologic predictors of tu-

mor response to therapy.

evaluation); a $12 \%$ margin positivity that the authors feel likely would not have been avoided with an open operation; and, only a median follow-up of 11 months.

Although these findings do add to the growing outcome database using I-O for resectable NSCLC, it remains challenging to make definitive comparisons between studies due to the inconsistent reporting of perioperative metrics, as noted in Table 2 of their results. Much like the 7 personalities cross that bridge to work, we must keep constant the 7 areas in design and reporting of similar trials to adequately compare surgical outcomes:

1. Patient selection: histologic heterogeneity, demographics.

2. Pretreatment evaluation: preoperative imaging, invasive nodal evaluation, biologic marker status (eg, programmed death-1/programmed cell death ligand 1). 